\title{
A fine structure study on osteogenesis of mesenchymal stem cells cultured with a 3D collagen scaffold
}

\author{
Shunji Kumabe ${ }^{1}$, Michiko Nakatsuka ${ }^{1 *}$, Rie Iwai ${ }^{2}$, Katsura Ueda ${ }^{1}$, Yoshifumi Matsuda ${ }^{1}$, Shosuke Morita ${ }^{2}$ and Yasutomo Iwai ${ }^{1}$ \\ ${ }^{1}$ Department of Oral Anatomy, Osaka Dental University, Osaka, Japan \\ ${ }^{2}$ Department of Oral and Maxillofacial Surgery (I), Osaka Dental University, Osaka, Japan
}

\begin{abstract}
We cultured human bone-derived mesenchymal stem cell(MSC)s (HMS0014:Yub621b) on a 3D collagen gel scaffold (Cellmatrix Type I-A) under non-inducing and inducing conditions in vitro. Conventional transmission electron microscopy (TEM) was performed for studying turnover of the MSCs and extracellular matrix (ECM) scaffold. The non-induced MSCs were fibroblast-like cells containing a variable number of membranous organelles and paraplasmic vesicles, and were characterised by elongated cell processes to ensheath reticular fibres; the Cellmatrix gel formed an interwoven fibrillar network in the ECM. Under inducing condition, MSCs were osteoinduced to differentiate into plurimorphic Ob-like cells extending thin elongated processes to make a cellular meshwork in the ECM scaffold. The fine structure study identified that osteoconduction was initiated with contact osteogenesis on the Cellmatrix collagen networks. A temporo-spatial replacement of fine Cellmatrix fibrils by collagen type I fibrils, and matrix vesicle- and appositional collagen-mediated mineralisation were found in the ECM scaffold. Results from this study suggest that mature HMS0014 Ob-like cells actively regulate the microenvironment to deposit osteoid tissue by the guided bone regeneration method (GBR) concepts.
\end{abstract}

\section{Introduction}

Many previous in vitro studies of culturing mesenchymal stem cell(MSC)s on the titanium (Ti) dental implant (IP) have shown that MSCs differentiated into osteogeneic osteoblast (Ob)-like cells, which commenced osteoconduction in direct bone-to-IP contact (BIC) formation at substrate surfaces of the IP under induction conditions. The mature Ob-like cells were secretory cells exhibiting early bone cell phenotype and late-stage osteogeneic differentiation [1-3]. In a recent scanning electron microscopy (SEM) study, we have observed that small polygonal human bone-derived HMS0014:Yub621b (fibroblastlike MSC, bone, human; Riken BRC, Tsukuba, Japan) cells proliferated and differentiated into large flat and pleomorphic cells sending out many cellular processes to attach on titanium (Ti) discs within 180 min culture under osteoinduction [4]. Findings of our histochemical studies revealed that Ob-like HMS0014 cells were activated to initiate osteogenic response since day 1 and thereby mineralising tissue being markedly deposited with calcification loci between days 7 and 14 of experiment. In addition, we recognised that ECM mineralisation significantly progressed in particular in 3D cultures [1,4-6].

The establishment of BIC interfaces was osteoinduction of the pre-Ob cells followed by cement line sedimentation and appositional hard tissue growth to induce osteogenesis phenomena at the substrate surface of the implant [2,7-11]. Furthermore, there have many studies revealed that seeding osteogenic MSCs on 3D scaffold or IPs coated with collagen could enhance cell-biomaterial interactions to promote the growth, differentiation and osteoconduction on Ti dental IPs [1,5,7,1215]. We preliminary estimated that Cellmatrix Type I-A fibrillar component formed an interwoven scaffold network for hard tissue formation by MSCs to surround Ti-IP test samples [11]. In the present study, therefore, we performed a transmission electron microscopy (TEM) examination of HMS0014: Yub621b cells 3D-cultured with
Cellmatrix Type I-A gel in vitro, and focused on turnover in Ob-like cells and mineralisation of the ECM scaffold.

\section{Materials and methods}

Immature HMS0014:Yub621b (fibroblast-like MSCs, bone, human; Riken BRC, Tsukuba, Japan) cells were filtrated, centrifuged, and then were incubated and maintained in POWEREDBY10 (GlycoTechnica Ltd., Sapporo, Japan) supplemented with $1 \%$ antibiotic-antimycotic agent (100units $/ \mathrm{mL}$ penicillin $+100 \mu \mathrm{g} / \mathrm{mL}$ streptomycin; Nacalai Tesque, Kyoto, Japan) in cell culture $75 \mathrm{~cm}^{2}$ flasks (TPP, Switzerland) at $37^{\circ} \mathrm{C}$ in humid air with $5 \% \mathrm{CO}_{2}$ for $72 \mathrm{~h}$.

\section{Tissue engineering of MSCs on 3D collagen gel scaffold}

$100 \mathrm{~mm}$ plastic tissue culture dishes (IWAKI, Tokyo, Japan) were paved with Cellmatrix Type I-A gel (base layer), paved with a layer of cell clusters containing immature HMS0014 cells in Cellmatrix Type I-A collagen gel (top layer, cell layer), and then overlaid with POWEREDBY10 (added with ascorbic acid $+\beta$ glycerophosphate+dexametazone; overlay medium) hence the cells were induced to different into osteogeneic Ob-like cells on the Cellmatrix scaffold in a 3D microenvironment $\left(1 \times 10^{6} \mathrm{cells} / \mathrm{mL}\right.$; humid $5 \% \mathrm{CO}_{2} / 37^{\circ} \mathrm{C}$, for 21 days) according to the "Collagen Gel Embedded

Correspondence to: Michiko Nakatsuka, Department of Oral Anatomy, Osaka Dental University, Osaka, Japan, Tel: +81-(0)72-864-3053; Fax: +81(0)72-864-3153;E-mail: naka-m@cc.osaka-dent.ac.jp

Key words: mesenchymal stem cell(MSCs), extracellular matrix (ECM) scaffold, guided bone regeneration method (GBR) tissue

Received: February 10, 2015; Accepted: February 28, 2015; Published: March 05,2015 
Culture Method" (http://www.nitta-gelatin.co.jp; Nitta Gelatin Inc.), and were designated as samples of the experimental group (the experimentals).

In contrast, HMS0014 cells co-cultured with Cellmatrix under non-inducing condition (without addition of osteogenic supplements) and maintained for 3 days following the same Cellmatrix embedded culture method were prepared for samples of the control group (the controls) in the present study.

\section{The histology of the experimental and control groups}

The samples containing 3D-cultured HMS0014 cells developed in the dishes under non-induced (the controls: days 1 and 3 samples) and induced (the experimentals: days 3, 7, 14 and 21 samples) culture conditions were dissected and prepared for the present study.

Tissues dissected from both the controls and experimentals were immersion-prefixed ( $1 \frac{1}{2}$ Karnovsky's fixatives), post-fixed $\left(1.0 \% \mathrm{OsO}_{4}\right)$ and embedded in EPON 812 (TAAB, Berkshire, UK). The Eponembedded samples were semi thin $(1-2 \mu \mathrm{m}$ thickness) and ultrathin (70-90nm thickness) sectioned with glass or diamond knives using an ultratome (ULTROTOME; LKB, Stockholm, Sweden), and prepared for survey light microscopy (LM) and conventional TEM.

The semi thin sections were picked up on slide glass, stained with $0.5 \%$ malachite green $\left(80^{\circ} \mathrm{C}, 60-100 \mathrm{sec}\right), 0.5 \%$ toluidine blue $\left(80^{\circ} \mathrm{C}\right.$, $30 \mathrm{sec}$ ) and $0.5 \%$ basic fuchsin (room temp, $10 \mathrm{sec}$ ). The specimens were immersed in cedar oil and embedded under a cover glass, and then observed and photographed under an Olympus BX41 LM mounted with an Olympus FX380 3CCD digital camera system (Olympus, Tokyo, Japan; OS: Windows XP, Microsoft, CA, USA). On the other hand, the ultrathin sections were picked up on 150-mesh copper grids; the specimens were electron stained with uranyl acetate and lead citrate, and then examined and photographed with a Hitachi H-7100 TEM (Hitachi, Tokyo, Japan) following the conventional methods.

The present GBR method osteoinduced human MSCs within a 3D collagen scaffold to actively regulate a homeostatic microenvironment for commencing osteoconduction in vitro.

\section{Results and discussion}

\section{Ob-like HMS0014 cells and the ECM in the cell layer}

Controls (days 1 and 3 specimens): The non-inducing HMS0014 cells were spherical, polygonal cells (dimension: $10 \mu \mathrm{m} \times 40 \mu \mathrm{m}$ ) MSCs characterised by dendritic pseudopodia which extended many long and thin cytoplasmic processes to ensheath reticular fibres (diameter $(d)=1-3 \mu \mathrm{m})$ consisting of fine collagen type III fibrils and ground substance [16]; MSCs thereby interconnecting to make a cellular meshwork in loose connective tissue of the cell layer (Figure 1a-1c). The fibroblast-like MSCs showed a high nucleus-to-cytoplasm (N/P) ratio, and the indented ovoid-shaped nucleus being finely distributed with hetero- and eu-chromatin. Fine structure examination revealed that the cytosol of the active MSCs under non-inducing condition was rich in ribosomes, and the cytoplasm contained well-developed Golgi complexes, rough endoplasmic reticulum (ER) studded with electron dense material, abundant elongated mitochondria in the orthodox configuration, and a few phagosomal lysosomes (Figure 1b).

In the ECM, we observed that the Cellmatrix collagen networks were composed mainly of thin $(\mathrm{d} \fallingdotseq 10 \mathrm{~nm}$, band interval=indistinct $)$ fibrils intermingled with a few thick $(\mathrm{d}=15-30 \mathrm{~nm}$, band interval $\mathrm{d} \fallingdotseq 20$ nm) fibrils (Figure 1d).
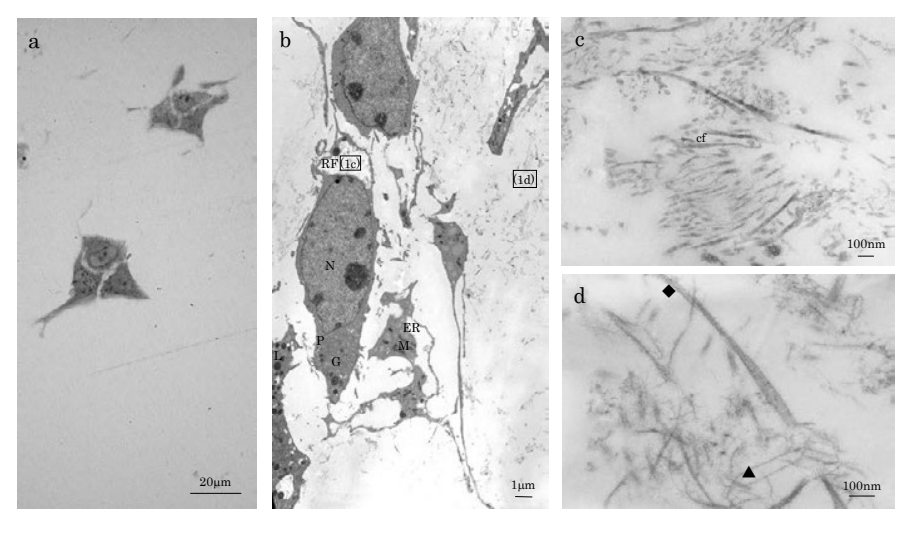

Figure 1. LM \& TEM of non-inducing HMS0014 cells cultured with Cellmatrix scaffold (day 3 control). 1a) LM of the MSC clusters. 1b) TEM indicates that the MSCs are fibroblastlike cells representing immature type of osteogeneic cells (N: nucleus, P: cytoplasm, ER: endoplasmic reticulum, M: mitochondrion, L: lysosome, G: Golgi apparatus). 1c) The MSCs have long and thin cytoplasmic processes to ensheath the reticular fibre (RF) containing thin collagen fibrils (cf) and amorphous materials. 1d) Cellmatrix collagen fibrils ( $\boldsymbol{\Lambda}$ : thin fibrils $\mathrm{d} \fallingdotseq 10 \mathrm{~nm}$, indistinct band interval, $\diamond$ : thick fibrils; $\mathrm{d}=15-30 \mathrm{~nm}$, band interval $=20 \mathrm{~nm})$ are distributed in the ECM.

The findings indicated that the non-inducing MSCs 3D-cultured in Cellmatrix Type I-A gel for 3 days were secretory linage cells, but were not yet activated to initiate osteogeneic response or differentiate into bone-forming osteoblast (Ob)s (Figure 1a-1d).

\section{Experimentals (day 3 to day 21 specimens)}

TEM showed that osteoinduced HMS0014 Ob-like cells had a bulging cell body (dimension: $30 \mu \mathrm{m} \times 90 \mu \mathrm{m}-100 \mu \mathrm{m} \times 200 \mu \mathrm{m}$ ) abundant in cytoplasm showing low N/P ratio. The cells extended many flat lamellipodia and dendritic filopodia with structural surface modification of many microvilli; the cells were closely intracellularly junctions. The cytoplasm was rich in ribosomes and morphoplasms, e.g. membranous organelles of well-developed ER and Golgi apparatus, and many mitochondria exhibiting the orthodox configuration with the inner compartment filled with abundant electron-dense matrix (Figure $2 \mathrm{a}-2 \mathrm{~b})$. Furthermore, small smooth-surface paraplasmic vesicles $(\mathrm{d} \fallingdotseq 150 \mathrm{~nm})$ distributed nearby and at the cell membrane and many paraplasmic vesicles closely related with characteristic electron-dense lysosomes were observed. The membranous structures were estimated to be the morphoplasm supporting the stable and maturation models for vesicular transport (trafficking) mechanisms of the mature Ob-like cells. Other than vesicle budding, microapocrine secretion of matrix vesicles (MVs; $d=30-300 \mathrm{~nm}$ ) at the cell membrane was demonstrated (Figure 2b).

TEM observed that the cytosol of the day $21 \mathrm{Ob}$-like cells was filled with a well-developed cytoskeletal network consisting of microfilaments $(\mathrm{d}=3-6 \mathrm{~nm})$, intermediate filaments $(\mathrm{d} \fallingdotseq 10 \mathrm{~nm})$ and microtubules $(d=20-25 \mathrm{~nm}$; Figure $3 \mathrm{c})$. Also we found that the nucleolemma of day $21 \mathrm{Ob}$-like cells showed dilated nuclear pores and perinuclear cisternal space filled with electron-condense substance; the disintegrating nucleolemma enveloped some patches of condensed chromatin and many enlarged autophagic vacuoles (Figure 3a). The histology indicated that Ob-like cells in the growing tissue-engineered tissue were entering the terminal phase of autophagic degeneration, a type of non-apoptotic programmed cell death in the $21^{\text {st }}$ day of experiment. Gap junctions (GJS) connecting degenerative cells and adjacent cells were evident (Figure 3a-3b). 


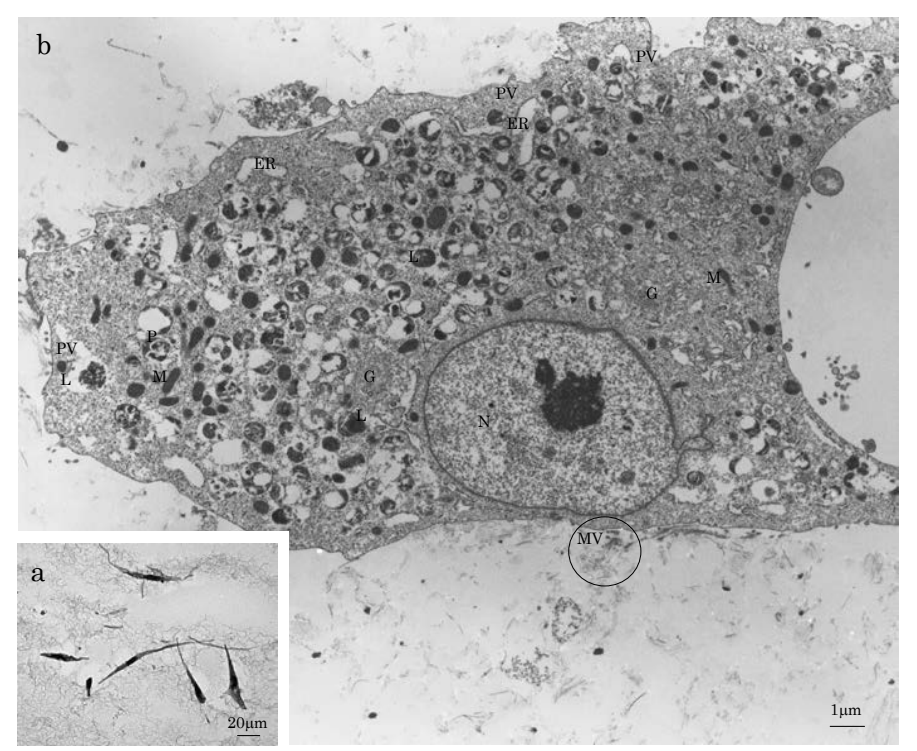

Figure 2. LM \& TEM of HMS0014 cells of the day 7 experimental group. 2a) The LM shows Ob-like cells in the Cellmatrix meshwork. 2b) The osteoinduced HMS0014 Oblike cells have a bulging cell body abundant in cytoplasm showing low N/P ratio. (N: nucleus, P: cytoplasm, ER: endoplasmic reticulum, G: Golgi apparatus, M: mitochondrion, L: lysosome.PV: paraplasmic vesicle). Both matrix vesicles (MV; $\mathrm{d}=40-300 \mathrm{~nm})$ and collagen-mediated mineralisation events are found nearby the Ob-like cell (circled area).
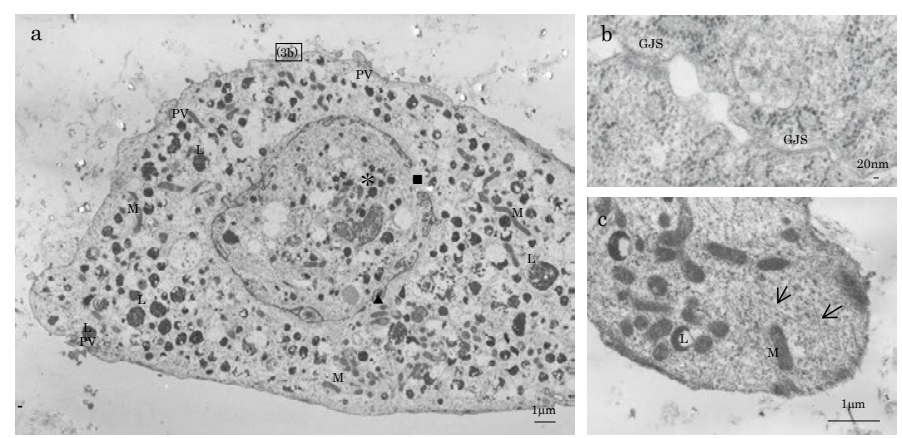

Figure 3. TEM of a day 21 experimental HMS0014 cell. 3a) The nucleolemma of day the $21 \mathrm{Ob}-\mathrm{like}$ cells shows dilated nuclear pores and perinuclear cisternal space filled with electron-condense substance (L: lysosome, M: mitochondrion, PV: paraplasmic vesicle, $\boldsymbol{\Delta}$ : perinuclear cisternal space, $\mathbf{m}$ dilated nuclear pore, $*$ : autophagic vacuole). $3 \mathrm{~b}$ ) TEM shows GJS connecting degenerative day 21 experimental Ob-like cells. 3c) The cytosol of the day $21 \mathrm{Ob}-$ like cell is filled with a well-developed cytoskeletal network $(\uparrow)$.

LM of the cultures under inducing condition revealed that Cellmatrix collagen gel of the base layer sent out branches to blend with the ECM scaffold of the cell (top) layer in the experimental specimens. The cell layer was distributed with plurimorphic cells extending elongated processes, faintly stained fine fibrils and ground substance (Figure 4a; day 7, Figure 4b; day 3). On the other hand, TEM studies observed that Cellmatrix collagen gel branches distributing at the peripheries of the base layer were divided into collagen warps and wefts (fibres; $\mathrm{d} \fallingdotseq 1 \mu \mathrm{m}$ ) which further spread out fine fibrils spreading into the cell layer (Figure 4a, 4c-4f; days $7 \& 14$ ). The Cellmatrix fibres were composed of fibrillar collagen $(\mathrm{d}=10-40 \mathrm{~nm}$, band interval=indistinct to $20 \mathrm{~nm}$ ) and amorphous ground substance which blended into the ECM sealing the space between neighboring Ob-like HMS0014 cells. Furthermore, the present TEM of the days 3-14 experimental specimens showed that at the vicinity to the plasma membrane, there were distribution of matrix vesicles (MVs) and accumulation of thin collagen type I fibrils $(\mathrm{d}=25-40 \mathrm{~nm}$, band interval=50-60nm) extending towards the central portion of the intercellular ECM. The fine structure findings indicated formation of a 3D ECM scaffold connecting the base and cell layers.

Sedimentation of cement line and collagen-mediated mineralisation were found contributing to contact osteogenesis phenomenon occurred on the peripheries of Cellmatrix fibres in the ECM scaffold). In contrast, both MV- and collagen-mediated mineralisation events $(\mathrm{d}=100$ $280 \mathrm{~nm}$ ), needle-like crystallite deposition and subsequent accretion of calcospherite and calcified locus (dimension $=1.0 \mu \mathrm{m} \times 1.0 \mu \mathrm{m}$ to $2.0 \mu \mathrm{m} \times 5.0 \mu \mathrm{m})$ formation arose at spatially/structurally sites by the nucleation phenomena, which occurred adjacent to Ob-like cells and along collagen fibrils (of the Cellmatrix scaffold and what secreted
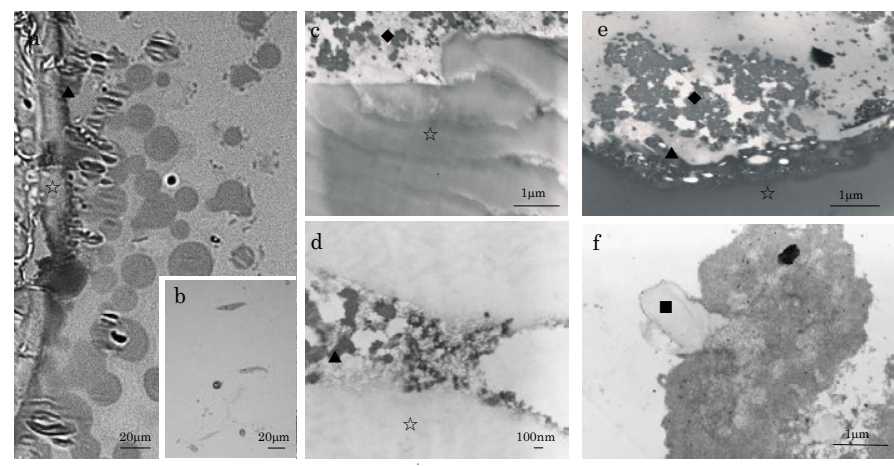

Figure 4. LM \& TEM of the day 21 experimental HMS0014 cells cultured under inducing condition. 4a) LM of a semithin section showing the base and cell layers of a day 21 experimental specimen; sedimentation of cement line $(\boldsymbol{\Delta})$ at the periphery of Cellmatrix scaffold ( $(5)$ is found. 4b) TEM indicates that the cell layer is distributed with plurimorphic cells extending fine elongated processes. 4c-e) TEM shows sedimentation of an afibrillar cement line $(\boldsymbol{\Delta})$ at the periphery of Cellmatrix scaffold $(\boldsymbol{\Sigma})$ and collagen-mediated mineralisation ( $)$ in the ECM, and therefor obtain a direct osteogenesis of tissueengineering tissue on the Cellmatrix Type I-A 3-D scaffold . 4f) In the central ECM, TEM shows mineralisation related with Cellmatrix Type I-A collagen (घ).

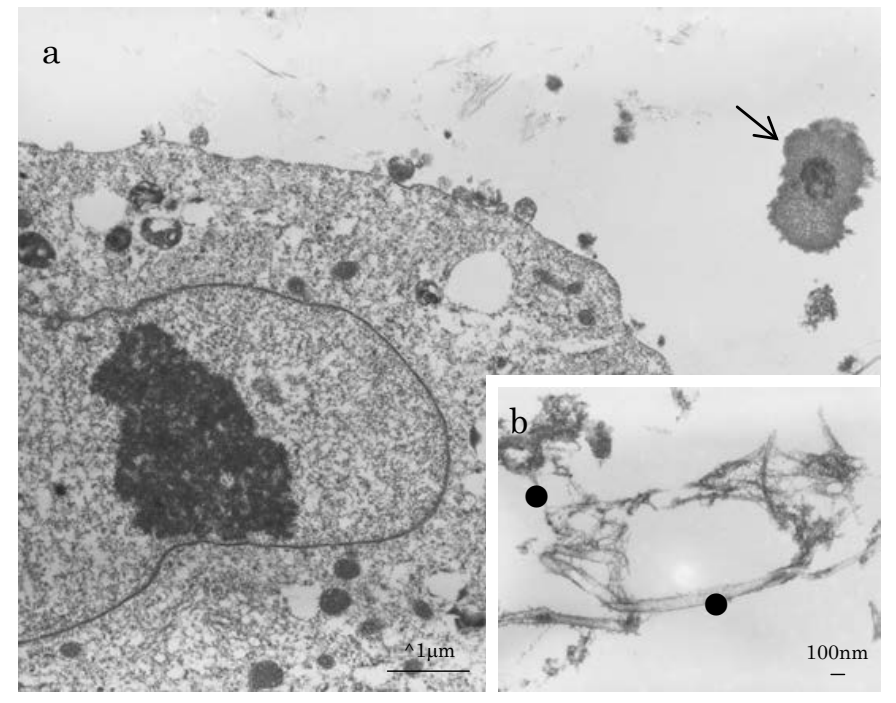

Figure 5a-b: 5a-b) TEM of the day 7 experimental group. 5a) Collagen-mediated mineralisation and calcification loci $(\uparrow)$ formation closely related with the Cellmatrix Type I-A collagen scaffold meshwork are observed. 5b) In the central region of the intercellular ECM, distribution of Cellmatrix Type I-A collagen fibrils $(\bullet: \mathrm{d}=15-48 \mathrm{~nm}, 20 \mathrm{~nm}$ avg.) with indistinct bandings ( $20 \mathrm{~nm}$ bandings) is demonstrated . 
by the Ob-like cells) were demonstrated in the ECM of the cell layer between days 3 and 14 of experiment (Figure $5 a-5 b$ ). The present TEM also revealed MV- and collagen-mediated calcification in the ECM scaffold of the experimental day 21 specimens. However, Cellmatrix fibres or fibrils were hardly identified in the ECM of the day 21 specimens (Figure 6).

Previously, we have studied MSCs cultured on Ti test samples subjected to different surface substrate modifications under inducing condition, and obtained results to indicate that immature MSCs were osteoinduced within 180 minutes, and differentiated into mature Oblike cells during three days of culture $[1,4,5,10,11]$. In the present study, we 3D-cultured HMS0014 MSCs on Cellmatrix Type I-A gel, and in particular investigated the turnover of cells and ECM scaffold under induction condition. Findings of the study demonstrated that the HMS0014 MSCs were clusters of intercellular-connected fibroblastlike cells representing a more immature type of osteogenesis; the MSCs were distributed in amorphous ground substance containing thin microfibrils $(\mathrm{d} \fallingdotseq 10 \mathrm{~nm}$, band interval $=$ indistinct $)$ intermingled with a few thicker fibrils $(\mathrm{d}=15-30 \mathrm{~nm}$, band interval $\mathrm{d} \fallingdotseq 20 \mathrm{~nm})$ of the Cellmatrix collagen under non-inducing condition (the controls) [1618]. In contrast, results of the TEM investigation of the experimentals cultured under induction condition indicated that the Cellmatrix gel fabricated a complicated network of collagen fibres $(\mathrm{d} \fallingdotseq 1 \mu \mathrm{m})$ which divided into fibrils/microfibrils $(\mathrm{d}=10-40 \mathrm{~nm}$, band interval=indistinct

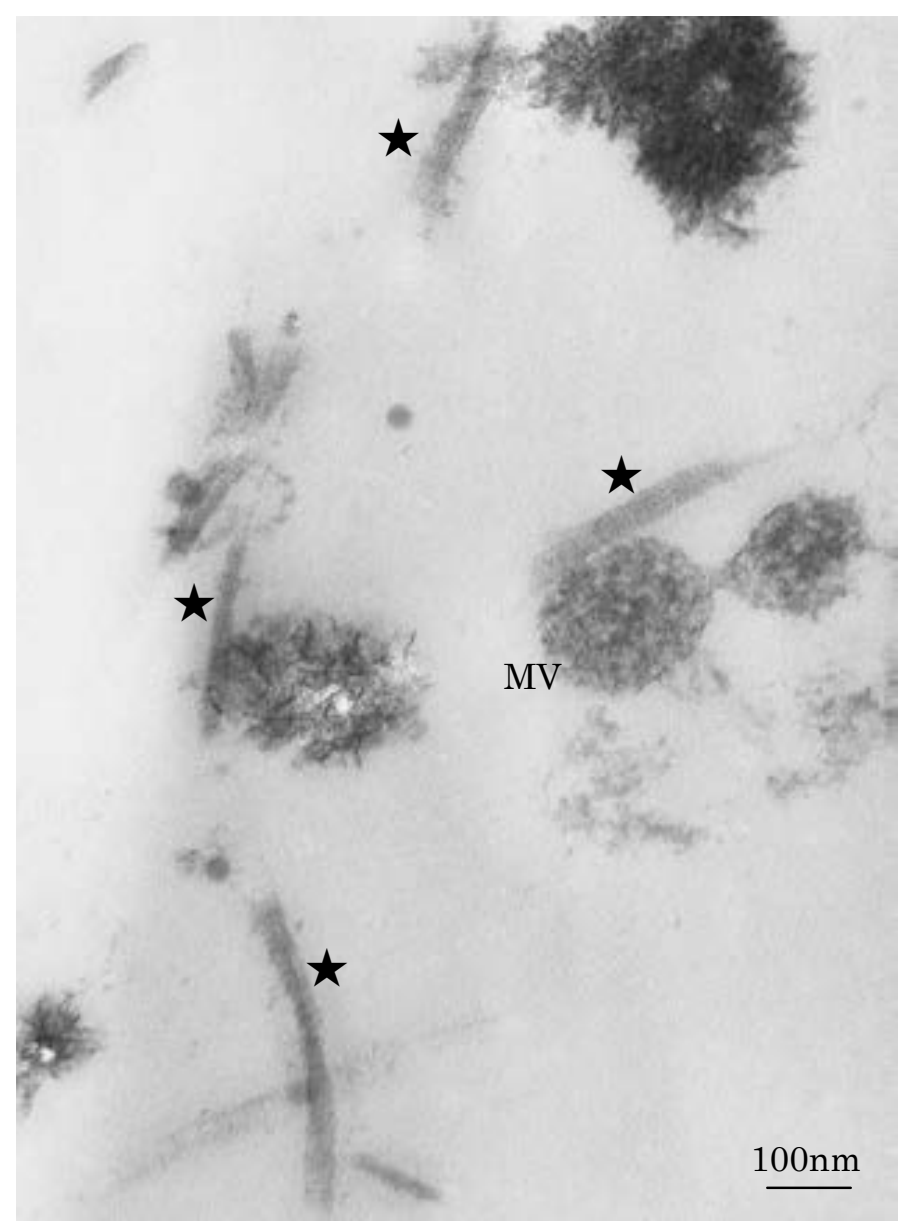

Figure 6. TEM of the day 21 experimental group. Matrix vesicle (MV)- and Type I collagen ( $\star: \mathrm{d}=30-40 \mathrm{~nm}$, bandings $=60-70 \mathrm{~nm}$ )-mediated calcification in the ECM are identified; Cellmatrix fibres or fibrils were hardly identified in the ECM of the day 21 specimens. to $20 \mathrm{~nm}$ ) to disperse in the intercellular spaces containing also collagen type I secreted by osteoinduced Ob-like cells, thereby contributed to the ECM scaffold containing hybrid collagen fibrils. On the other hand, we revealed sedimentation of cement line to enhance contact osteogenesis at the peripheries of Cellmatrix fibres which consisted of fibrillar collagen and amorphous ground substance. Meanwhile, the TEM demonstrated both MV- and collagen-mediated mineralisation events occurred nearby the Ob-like cells and along hybrid collagen type I and Cellmatrix fibrils distributed in the ECM. The findings indicated that mineralisation phenomenon of the hybrid fibrils and an increased collagen type I secretion by the active Ob-like cells resulted in changes of the fibrillar component in ECM scaffold. The Cellmatrix collagen in the ECM scaffold was temporo-spacially replaced by collagen type I; Cellmatrix fibres/fibrils were not evident in the day 21 experimental specimens.

On the other hand, the present TEM study revealed that the welldeveloped cytoskeleton and abundant membranous organelles in particular mitochondria of orthodox configuration, and distribution of coated vesicles and endosomes spatially closely related with lysosomes were general characteristics of the mature experimental days 3-21 Oblike HMS0014 cells. We observed budding of small smooth-surface vesicles nearby/at the cell membrane, as well as accumulation of nascent/thin collagen fibrils and microapocrine secretion of MVs at the periphery of cell membrane in the ECM; the intracellular morphplasms were organelles and paraplasms related with vesicular transport and trafficking mechanisms of the osteogeneic Ob-like cells [19-22].

Many studies have reported that the intracellular actin filament cortex maintained and regulated the cell shape and generation of mechanical forces in cell migration [6,22]. Furthermore, stress fibres of the cortex architecture were developed to couple with focal adhesion plaques for conductance of forces towards the substrate and scaffolds, so that chemical and physical signals occurred at the focal adhesions were transmitted to the cell and subsequently shared with neighboring cells via intercellular junctions [23-26]. Taken together, the results of these histological studies revealed that intracellular cytoskeletal elements were organised to be a tension-bearing structure, which gave 3D structural support to carry out cellular movements and conveyed information/signals about the microenvironment of the cells $[22,27,28]$. Our previous SEM studies have demonstrated that Ob-like cells spread well on the surface of Ti-based test samples under inducing conditions $[4,5,10,11]$. In the present TEM study, we observed that osteo-induced Ob-like HMS0014 cells contained many microfilaments, intermediate filaments and microtubules in the cell body and peripheral cytoplasm. We speculated that the distribution of the F-actin cytoskeleton was corresponding with actin stress fibres contributing to focal adhesion formation, which was co-localised with the expression of F-actin and CD51 in our previous fluorescent immunomicroscopy of HMS0014 cells cultured under inducing conditions $[4,5,10,11]$.

In the present study, we observed that some of the day $21 \mathrm{Ob}$-like cells were characterised with ultrastructural evidences of distribution of numerous lysosomes in the cytoplasm and the disintegrated nucleolemma enveloping patches of condensed chromatin and many electron-dense autophagic vacuoles. The histology demonstrated the occurrence of non-apoptotic programmed cell death, and was indicative for progressive autophagic degeneration of the surviving osteogeneic cells in the day 21 3D-cultured GBR tissue [29,30]. Many studies have stated that the recycling function of autophagy through a lysosomal degradation pathway essentially maintained homeostasis and the survival of cells [30-32]. The present study found that the 
experimental cells were interconnected by GJS channels for allowing the transmission of electrical impulses among their neighbouring cells to play an important function in the coordination of Ob-like cell turnover and energy homeostasis by spreading and moderating cellkilling signals to also cause the bystander effects between contacting cells [23-28,33-35].

It has been reported by several studies that tissue engineering for GBR by the placement of MSCs within a biodegradable scaffold decreased in the need for recruitment of osteogeneic cells at a bone defect site [36-38]. We previously reported that KUSA/A1 mouse MSCs GBR-engineered in 3D Cellmatrix Type I-A Gel collagen networks contributed to contact osteogenesis providing direct BIC with Ti dental IPs $[1,4,6,8]$. The present TEM study revealed that the active Ob-like HMS0014 cells contained the morphoplasm providing for the vesicular transport and trafficking mechanisms, as well as demonstrated histological findings related to the turnover and interactions between the cells and ECM that enhanced osteoconduction of the ECM scaffold. Moreover, we identified configuration of GJSs related with autophagymediated programmed cell death of the Ob-like cells survived in the mineralising osteoid tissue [20,30-32,34].

\section{Acknowledgements}

This work was supported by a grant-in-aid for scientific research (C) (24592976) from the Ministry of Education, Culture, Sports, Science, and Technology of Japan. The human mesenchymal stem cells line, HMS0014 (Yub621b), was provided by the RIKEN BRC through the National Bio-Resource Project of the MEXT, Japan. The study was performed using the Laboratory Animal, Morphological Research and Tissue Culture Facilities in the Institute of Dental Research, Osaka Dental University.

\section{References}

1. Mikami T, Kumabe S, Y Iwai (2010) A study of osseointegration -3D culture of KUSA/A1 cells with a collagen scaffold on titanium implants with different surface modifications. J Oral Tissue Engin 8: 60-73.

2. Anselme K (2000) Osteoblast adhesion on biomaterials. Biomaterials 21: 667-681. [Crossref]

3. Boyan BD, Lossdörfer S, Wang L, Zhao G, Lohmann CH, et al. (2003) Osteoblasts generate an osteogenic microenvironment when grown on surfaces with rough microtopographies. Eur Cell Mater 6: 22-27. [Crossref]

4. Iwai Y, Matsuda Y, Nakatsuka M, Mikami Y, Kumabe S (2012) A preliminary study of the dental implant therapy - initial osteogenesis of human mesenchymal stem (HMS0014) cells on titanium discs with different surface modifications. Okajimas Folia Anat Jpn 88: 133-140. [Crossref]

5. Nakatsuka M, Hashimoto Y, Kumabe S, An C, Ueda K, et al. (2010) The study of cell attachment and hard tissue formation on the dental implant surface [Abstract]. Kaibougaku Zasshi 85: 177.

6. Salido M, Vilches JI, Gutiérrez JL, Vilches J (2007) Actin cytoskeletal organization in human osteoblasts grown on different dental titanium implant surfaces. Histol Histopathol 22: 1355-1364. [Crossref]

7. Meyer U, Büchter A, Wiesmann HP, Joos U, Jones DB (2005) Basic reactions of osteoblasts on structured material surfaces. Eur Cell Mater 9: 39-49. [Crossref]

8. Marco F, Milena F, Gianluca G, Vittoria O (2005) Peri-implant osteogenesis in health and osteoporosis. Micron 36: 630-644. [Crossref]

9. Koyano K, Matsushita Y, Ayukawa Y (2009) Basic science for the dental implantology. In: Koyano K, Matsuura M, eds. Essential oral implantology. Ishiyaku Publishers Inc., Tokyo, JAPAN (in Japanese).

10. Iwai Y, Mikami Y, Nakatsuka M, Huang HC, Mikami H, et al. (2012) A preliminary study of the dental implant therapy -initial osteogenesis of human mesenchymal stem (HMS0014) cells on titanium discs and implants with different surface modifications. $J$ Tissue Eng Regen Med 6 (Suppl. 1): 234-235.
11. Kumabe S, Nakatsuka M, Ueda K, An C, Inui-Yamamoto C, et al. (2013) Hard tissue formation and change of extracellular matrix by 3-D cultured HMS0014 cells using a collagen scaffold. AATEX 18 (Suppl): 234.

12. Davies JE (2003) Understanding peri-implant endosseous healing. J Dent Educ 67: 932-949. [Crossref]

13. Isaac J, Loty S, Hamdan A, Kokubo T, Kim HM, et al. (2009) Bone-like tissue formation on a biomimetic titanium surface in an explant model of osteoconduction. $J$ Biomed Mater Res A 89: 585-593. [Crossref]

14. Peppas NA, Langer R (1994) New challenges in biomaterials. Science 263: 1715-1720. [Crossref]

15. Mushahary D, Wen C, Kumar JM, Lin J, Harishankar N, et al. (2014) Collagen type-I leads to in vivo matrix mineralization and secondary stabilization of $\mathrm{Mg}-\mathrm{Zr}-\mathrm{Ca}$ alloy implants. Colloids Surf B Biointerfaces 122: 719-728. [Crossref]

16. Mohammad AA, Asai J (1993) Ultrastructural and morphometrical studies on the reticular framework and reticular fibers in the reticuloendothelial system of rats. Nagoya J Med Sci 55: 47-56. [Crossref]

17. Ozen A, Sancak IG, Von Rechenberg B, Koc S (2013) Ultrastructural characteristics of sheep and horse mesenchymal stem cells (MSCs). Microsc Res 1: doi:10.4236/ mr.13004.

18. Sathananthan H, Pera M, Trounson A (2002) The fine structure of human embryonic stem cells. Reprod Biomed Online 4: 56-61. [Crossref]

19. Albrektsson T, Johansson C (2001) Osteoinduction, osteoconduction and osseointegration. Eur Spine J 10 (Suppl 2): S96-101.

20. Watanabe T, Sakai Y, Hira Y, Bochimoto H, Hosaka M (2008) Molecular and cellular basis for the secretory granule biogenesis in endocrine cells. Microscopy 43: 29-34. (in Japanese)

21. Kaasik A, Safiulina D, Zharkovsky A, Veksler V (2007) Regulation of mitochondrial matrix volume. Am J Physiol Cell Physiol 292: C157-163. [Crossref]

22. Lim JY, Taylor AF, Li Z, Vogler EA, Donahue HJ (2005) Integrin expression and osteopontin regulation in human fetal osteoblastic cells mediated by substratum surface characteristics. Tissue Eng 11: 19-29.

23. Rosendaal M, Green CR, Rahman A, Morgan D (1994) Up-regulation of the connexin $43+$ gap junction network in haemopoietic tissue before the growth of stem cells. J Cell Sci 107: 29-37. [Crossref]

24. Shapiro F (1997) Variable conformation of GAP junctions linking bone cells: a transmission electron microscopic study of linear, stacked linear, curvilinear, oval, and annular junctions. Calcif Tissue Int 61: 285-293.

25. Donahue HJ (2000) Gap junctions and biophysical regulation of bone cell differentiation. Bone 26: 417-422. [Crossref]

26. Yap AS, Kovacs EM (2003) Direct cadeherin-activated cell signalling: a view from the plasma membrane. J Cell Biol 160: 11-16.

27. Guo Y, Martinez-Williams C, Rannels DE (2003) Gap junction-microtubule associations in rat alveolar epithelial cells. Am J Physiol Lung Cell Mol Physiol 285: L1213-1221. [Crossref]

28. Lu JG, Sun YN, Wang C, Jin de J, Liu M (2009) Role of the alpha v-integrin subunit in cell proliferation, apoptosis and tumor metastasis of laryngeal and hypopharyngeal squamous cell carcinomas: a clinical and in vitro investigation. Eur Arch Otorhinolaryngol 266: 89-96. [Crossref]

29. Mizushima N (2004) Methods for monitoring autophagy. Int J Biochem Cell Biol 36 2491-2502. [Crossref]

30. Kitanaka C (2005) Non-apoptotic programmed cell death: existence and significance of programmed cell deaths having morphology and mechanism distinct from apoptosis. Yamagata Med J 23:83-96.

31. Levine B, Yuan J (2005) Autophagy in cell death: an innocent convict? J Clin Invest 115: 2679-2688. [Crossref]

32. Apel A, Zentgraf H, Büchler MW, Herr I (2009) Autophagy-A double-edged sword in oncology. Int J Cancer 125: 991-995. [Crossref]

33. Mesnil M, Piccoli C, Tiraby G, Willecke K, Yamasaki H (1996) Bystander killing of cancer cells by herpes simplex virus thymidine kinase gene is mediated by connexins. Proc Natl Acad Sci U S A 93: 1831-1835. [Crossref] 
34. Krutovskikh VA, Piccoli C, Yamasaki H (2002) Gap junction intercellular communication propagates cell death in cancerous cells. Oncogene 21: 1989-1999. [Crossref]

35. Frank DK, Szymkowiak B, Josifovska-Chopra O, Nakashima T, Kinnally KW (2005) Single-cell microinjection of cytochrome $\mathrm{c}$ can result in gap junction-mediated apoptotic cell death of bystander cells in head and neck cancer. Head Neck 27: 794800. [Crossref]
36. Bartold PM, McCulloch CA, Narayanan AS, Pitaru S (2000) Tissue engineering: a new paradigm for periodontal regeneration based on molecular and cell biology. Periodontol 2000 24: 253-269. [Crossref]

37. Hämmerle CH, Jung RE (2003) Bone augmentation by means of barrier membranes. Periodontol 2000 33: 36-53. [Crossref]

38. Sparks MS, Kerns DG, Wilson TG, Hallmon WW, Spears R, et al. (2007) Bone regeneration around implants in the canine mandible with cultured fibroblasts in polyglactin mesh. J Periodontol 78: 1276-1287. [Crossref]

Copyright: $\mathbb{0} 2015$ Kumabe S. This is an open-access article distributed under the terms of the Creative Commons Attribution License, which permits unrestricted use, distribution, and reproduction in any medium, provided the original author and source are credited. 